\title{
AhR-E2F1-KGFR signaling is involved in KGF-induced intestinal epithelial cell proliferation
}

\author{
KUNQIU YANG, JIUHENG YIN, BAIFA SHENG, QIMENG WANG, BIN HAN, \\ AIMIN PU, MIN YU, LIHUA SUN, WEIDONG XIAO and HUA YANG
}

\begin{abstract}
Department of General Surgery, Xinqiao Hospital, Third Military Medical University, Chongqing 400037, P.R. China
\end{abstract}
Received January 2, 2016; Accepted February 9, 2017

DOI: $10.3892 / \mathrm{mmr} .2017 .6368$

\begin{abstract}
Keratinocyte growth factor (KGF) stimulates intestinal epithelial cell proliferation upon binding to the KGF receptor (KGFR). The activated aryl hydrocarbon receptor (AhR) serves an important role in the development of tissues by promoting the expression of AhR receptors, which can regulate cell proliferation. In the present study, the signaling pathway between AhR and KGFR in investigated with regards to KGF-induced intestinal epithelial cell proliferation. Male C57BL/6J wild type and $\mathrm{AhR}^{-1-}$ mice, were randomized into four groups: Control, KGF, $\mathrm{AhR}^{-/}+\mathrm{KGF}$ and $\mathrm{AhR}^{-/-}$( $\mathrm{n}=6$ per group). The small bowel was harvested on day 5 post-treatment. LoVo cells were used to study signaling pathways in vitro and were divided into the following four treatment groups: DMSO, KGF, $\mathrm{KGF}+$ small-interfering (si)AhR and siAhR. In vivo, knockdown of AhR mRNA transcripts may abolish KGF-induced intestinal epithelial cell proliferation. Furthermore, KGFR expression was downregulated following knockdown or silencing of AhR expression in vivo and in vitro. The present study identified that the transcription factor E2F1 could regulate KGFR expression, and that siAhR treatment led to reduced expression of E2F1 in the nucleus and inhibited KGF-induced cell proliferation. In conclusion, the current results demonstrated that the AhR-E2F1-KGFR pathway is involved in KGF-induced intestinal epithelial cell proliferation.
\end{abstract}

\section{Introduction}

Interactions between intestinal epithelial cells and intraepithelial lymphocytes (IELs) serve an important role

Correspondence to: Professor Hua Yang, Department of General Surgery, Xinqiao Hospital, Third Military Medical University, 183 Xinqiao Main Street, Shapingba, Chongqing 400037, P.R. China E-mail: huayang@tmmu.edu.cn

Key words: keratinocyte growth factor receptor, aryl hydrocarbon receptor, keratinocyte growth factor, intestinal epithelial cell, proliferation in the growth and maintenance of the intestinal epithelium (1-3). Keratinocyte growth factor (KGF) is a member of the fibroblast growth factor (FGF) family. It is thought that KGF, which is expressed by gamma delta $(\gamma \delta)$ intraepithelial lymphocytes (IEL) in the mucosal layer (1), has an important involvement in promoting epithelial cell growth in a paracrine manner after it interacts with the KGF receptor (KGFR) (4,5). Previously, the authors reported that exogenous KGF may protect the small intestine from ischemia-reperfusion injury (I/R) and radiation-induced intestinal damage by promoting intestinal epithelial cell proliferation $(2,6)$. In addition, previous studies have reported that KGFR is abundantly expressed in the gastrointestinal tract, suggesting that the gut can both synthesize and respond to KGF (7-9).

Previously, the aryl hydrocarbon receptor (AhR) has been reported to be a significant factor in KGF-induced regenerative growth in a zebrafish model (10). Furthermore, AhR expression may be regulated by FGF in murine 3 T3 fibroblasts (11), which indicates that endogenous AhR might participate in FGF-mediated signaling.

AhR is a DNA binding protein that belongs to the basic region-helix-loop-helix superfamily (4) and is expressed by most cells. Unliganded AhR in the cytoplasmic compartment can form a stable complex with HSP90 (12). However, when the ligand for AhR activates this transcription factor, the AhR-ligand complex translocates to the nucleus and subsequently binds with the AhR nuclear translocator at dioxin-responsive elements, leading to the transactivation of several genes that encode phase I and II xenobiotic metabolizing enzymes, such as cytochrome P450s $(5,7,13)$. For several decades, the toxic effects mediated by AhR have been extensively studied (13-15). However, increasing evidence indicates that AhR may serve an important role in the regulation of receptor-mediated signaling. For example, Lee et al (16) reported that Notch1 is a downstream target of AhR based on microarray analysis of Ror $\gamma \mathrm{t}^{+}$cells from wild type and AhR-deficient mice. In addition, Qiu et al (17) suggested that the expression of IL-7R $\alpha$ was reduced by AhR ablation, and Kiss et al (18) reported that the expression of cKit was markedly lower in $\mathrm{AhR}^{-/}$innate lymphoid cells (ILCs). Based on these findings, it was hypothesized that endogenous AhR may affect the signals mediated by KGF through the regulation of KGFR expression. 


\section{Materials and methods}

Animals. C57BL/6 wild type (12 male; weight, $18-22 \mathrm{~g}$; age, 6-8 weeks) and C57BL/6 $\mathrm{AhR}^{+/-}$mice (2 female and 1 male; weight, 18-22 g; age, 6-8 weeks) were purchased from the Experimental Animal Center at Daping Hospital of the Third Military Medical University (Chongqing, China). Animals were bred and maintained under specific pathogen-free conditions in a temperature-controlled room $\left(20 \pm 2^{\circ} \mathrm{C}\right)$ with circadian light-dark cycles and free access to standard rodent chow and water. All animal experiments were performed in accordance with the National Institutes of Health Guidelines for the Care and Use of Laboratory Animals (Bethesda, MA, USA). All animal protocols used in the current study were evaluated and approved by the Ethics Committee of Xinqiao Hospital, Third Military Medical University (Chongqing, China). Mice were bred in a scheme using $\mathrm{AhR}^{+/} \times \mathrm{AhR}^{+/-}$breeders to generate $\mathrm{AhR}^{-/-}$mice. Mice were randomly divided into the following four groups: Control ( $\mathrm{n}=6), \mathrm{KGF}(\mathrm{n}=6), \mathrm{KGF}+\mathrm{AhR}^{-/}(\mathrm{n}=6)$ and $\mathrm{AhR}^{-/}(\mathrm{n}=6)$ groups. Recombinant human $\mathrm{KGF}$ was intraperitoneally administered at $5 \mathrm{mg} / \mathrm{kg} / \mathrm{day}$ for 5 days preoperatively.

Materials. KGF was purchased from Sino Biological Inc. (cat. no. 10210-H07E-50; Beijing, China). Anti-GAPDH antibody (cat. no. AB-P-R001) was obtained from Goodhere Biotechnology (Hangzhou, China). Anti-E2F1 (cat. no. 12171-1-AP) and anti-PCNA (cat. no. 10205-2-AP) antibodies were purchased from Wuhan Sanying Biotechnology (Wuhan, China). The anti-KGFR (cat. no. sc-6930 HRP) antibody was purchased from Santa Cruz Biotechnology, Inc. (Dallas, TX, USA) and the Anti-AhR (cat. no. ab166611) antibody was purchased from Abcam (Cambridge, MA, USA).

LoVo cell culture. Dulbecco's modified Eagle's medium (DMEM)/Ham's F-12 medium (ratio, 1:1; cat. no. SH30023.01B; Thermo Fisher Scientific, Inc. Waltham, MA, USA) containing 10\% FBS (cat. no. SH30023.01B; Thermo Fisher Scientific, Inc.) was used to culture LoVo cells purchased from American Type Culture Collection (Manassas, VA, USA). Additionally, $100 \mathrm{IU} / \mathrm{ml}$ penicillin and $100 \mathrm{mg} / \mathrm{ml}$ streptomycin (cat. no. C0222; Beyotime Institute of Biotechnology, Haimen, China) were added to the medium. Cells were incubated at $37^{\circ} \mathrm{C}$ in a $5 \% \mathrm{CO}_{2}$ atmosphere. The medium was changed every 2 days. LoVo cells were sub-cultured following partial digestion with $0.25 \%$ trypsin and $0.53 \mathrm{mM}$ EDTA.

Knockdown of AhR and E2F1 mRNA transcripts by siRNA. Following culturing LoVo cells until reaching 30-40\% confluency in 6-well plates, they were transfected with siRNA (Guangzhou RiboBio Co., Ltd., Guangzhou, China) at a concentration of $50 \mathrm{nmol} /$ well using Lipofectamine 2000 (Invitrogen; Thermo Fisher Scientific, Inc., Waltham, MA, USA) in antibiotic-free and serum-free Opti-MEM medium according to the manufacturer's instructions. A random control siRNA (si-NC) was used as a negative control. Following $4 \mathrm{~h}$, the medium was replaced with normal LoVo cell medium, and the cells were cultured prior to use in experiments. The siRNA sequences used to target AhR were as follows: Sense, 5'-GGAACACCUACAUCUAGAA dTdT-3' and antisense,
3'-dGdT CCUUGUGGAUGUAGAUCUU-5'. The sequences use to target E2F1 were as follows: Sense, 5'-GGAACACCU ACAUCUAGAA dTdT-3' and antisense, 3'-dGdT CCUUGU GGAUGUAGAUCUU-5'.

Cell proliferation assays. Cell proliferation assays were conducted based on cell counting. LoVo cells were seeded in 96-well plates in a volume of $100 \mu \mathrm{l} /$ well and cultured in a 1:1 mixture of DMEM:Ham's F-12 medium containing 10\% FBS for $24 \mathrm{~h}$. The cells were transfected using AhR-siAhR. Trypsin was used to collect the cells, and a hemocytometer and trypan blue (cat. no. T8154; Sigma-Aldrich; Merck KGaA, Darmstadt, Germany) were used to count the number of viable LoVo cells. Numbers of cells per well were also assessed using flow cytometry analysis.

Flow cytometry analysis. Cells were plated in 6-well culture dishes in growth medium overnight prior to siRNA transfection. Following serum starvation for $24 \mathrm{~h}$, cells were stimulated with KGF $(100 \mathrm{ng} / \mathrm{ml})$ for $24 \mathrm{~h}$. Cells were then dissociated with $800 \mu$ l trypsin per well at $37^{\circ} \mathrm{C}$ for 3-5 min, and following adding $500 \mu \mathrm{l}$ DMEM/Ham's F-12 medium containing $10 \%$ FBS per well, cells were centrifuged at $1,000 \times \mathrm{g}$ at $4^{\circ} \mathrm{C}$ for 5 min. The supernatant was discarded and the cell pellet was washed with ice-cold PBS thrice with centrifugation at $1,000 \times \mathrm{g}$ at $4^{\circ} \mathrm{C}$ for $5 \mathrm{~min}$ after each wash. Cells were then fixed in $80 \%$ ethanol at $4^{\circ} \mathrm{C}$ overnight. Following 2 more washes with PBS, cells were treated with $0.1 \%$ Triton X-100, $5 \mathrm{mg} / \mathrm{ml}$ propidium iodide and $50 \mathrm{mg} / \mathrm{ml}$ ribonuclease A in PBS at $37^{\circ} \mathrm{C}$ for $15 \mathrm{~min}$ in the dark. Finally, $2 \times 10^{5}$ cells were analyzed by flow cytometry (MoFlo Astrios EQ; Beckman Coulter, Inc. Brea, CA, USA). The results were analyzed using FlowJo (version 9.0, FlowJo LLC, Asland, OR, USA).

RNA isolation and reverse transcription-quantitative polymerase chain reaction ( $R T-q P C R)$. Total RNA was isolated using TRIzol reagent (Takara Biotechnology Co., Ltd., Dalian, China) and was then reverse transcribed into cDNA using a PrimeScript ${ }^{\mathrm{TM}}$ RT reagent kit with gDNA Eraser (cat. no. RR047A; Takara Biotechnology Co., Ltd.). The primers used in the present study were as follows: KGFR (Invitrogen; Thermo Fisher Scientific, Inc.) forward, 5'-CGCGGATCC GCCGCCGGTGTTAACACCACGTACGGTCATCATCT GACAC-3' and reverse,5'-CGGAATTCACCATGCAGAGT GAAAGGATCGCCATCCTGGGAAGACTCC-3'; $\beta$-actin (Invitrogen; Thermo Fisher Scientific, Inc.) forward, 5'-CCA CGAAACTACCTTCAACTCC-3' and reverse, 5'-GTGATC TCCTTCTGCATCCTG-3'). qPCR was performed using the Fast SYBR ${ }^{\circledR}$ Green Master Mix (cat. no. 4385612; Thermo Fisher Scientific, Inc.), in a Rotor-Gene Q system (Qiagen $\mathrm{GmbH}$, Hilden, Germany) and with the following conditions: $94^{\circ} \mathrm{C}$ for $10 \mathrm{~min}$, then 45 cycles of $30 \mathrm{sec}$ at $94^{\circ} \mathrm{C}, 30 \mathrm{sec}$ at $60^{\circ} \mathrm{C}$, and $45 \mathrm{sec}$ at $72^{\circ} \mathrm{C}$. Relative fold changes in mRNA expression were calculated using the formula $2^{-\Delta \Delta \mathrm{Cq}}(19)$.

Western blotting. Total cell lysates were extracted using radioimmunoprecipitation lysis buffer $(10 \mathrm{mM}$ Tris $\mathrm{pH}$ 7.4, $20 \mathrm{mM} \mathrm{NaCl}, 5 \mathrm{mM} \mathrm{MgCl} 2,0.5 \%$ Nonidet P-40 and $0.1 \mathrm{mM}$ PMSF), and then protein lysates were centrifuged at $12,000 \times \mathrm{g}$ for $5 \mathrm{~min}$ at $4^{\circ} \mathrm{C}$. The protein concentrations 
were measured using a bicinchoninic acid assay kit (Beyotime Institute of Biotechnology, Haimen, China). Protein samples $(25 \mu \mathrm{g})$ were separated on 10\% SDS-PAGE gels, and the gels were electropheretically transferred to polyvinylidene difluoride membranes (EMD Millipore, Billerica, MA, USA). Membranes were blocked in $5 \%$ skim milk at $4^{\circ} \mathrm{C}$ for $1 \mathrm{~h}$ and incubated with anti-AhR (1:500 dilution), anti-KGFR (1:200 dilution), anti-E2F1 (1:1,000 dilution) or anti-GAPDH (1:1,000 dilution) antibodies for $24 \mathrm{~h}$ at $4^{\circ} \mathrm{C}$, followed by incubation for $1 \mathrm{~h}$ with the peroxidase-conjugated secondary antibody (1:5,000 dilution; cat no. BA1055/BA1051; Beyotime Institute of Biotechnology). Protein bands were detected using a Kodak Gel Logic 4000R Imaging System (Kodak, Rochester, NY, USA) with an enhanced chemiluminescence reagent (Boster Systems Inc., Pleasanton, CA, USA). The results were quantified using Carestream Molecular Imaging Software version 5.2.2 (Kodak).

Immunohistochemistry. Tissues were fixed in $4 \%$ paraformaldehyde at $4^{\circ} \mathrm{C}$ for $48 \mathrm{~h}$, and embedded in paraffin. Tissue sections (5 $\mu \mathrm{m}$ thick) were immersed in $3 \%$ hydrogen peroxide for $10 \mathrm{~min}$ to eliminate endogenous peroxidase activity and then were microwaved in $0.01 \mathrm{~mol} / 1$ citrate buffer (pH 6.0) thrice for $5 \mathrm{~min}$. PBS was used to wash the sections for each step. Samples were incubated at $4^{\circ} \mathrm{C}$ overnight with anti-PCNA antibody (1:100 dilution; cat. no. 10205-2-AP; Sanying Biotechnology, Wuhan, China), followed by a standard staining procedure using an LSAB kit (cat. no. SP-9000, Zhongshan Biotechnology Co, Ltd., Beijing, China). The crypt cell proliferation rate was calculated as the ratio of crypt cells that were positive for PCNA to the total number of crypt cells. The total number of proliferating cells/crypt was defined as the mean number of proliferating cells in ten crypts.

Nuclear protein extraction. Nuclear protein extraction was performed using the NE-PER Nuclear and Cytoplasmic Extraction Reagents kit (cat. no. 78833; Thermo Fisher Scientific, Inc.). Cells were harvested with trypsin-EDTA then centrifuged at $500 \mathrm{x} g$ at $4^{\circ} \mathrm{C}$ for $5 \mathrm{~min}$. For suspension, cells were harvested by centrifugation at $500 \times g$ at $4^{\circ} \mathrm{C}$ for $5 \mathrm{~min}$. Cells were washed by re-suspending the cell pellet in PBS. A total of $5 \times 10^{6}$ cells were transferred to a $1.5 \mathrm{ml}$ microcentrifuge tube and pelleted by centrifugation at $500 \mathrm{x} g$ at $4^{\circ} \mathrm{C}$ for $3 \mathrm{~min}$. The supernatants were discarded, leaving the cell pellet as dry as possible. Ice-cold CERI reagent $(40 \mu \mathrm{l})$ was added to the cell pellet, and then the tube was vortexed vigorously at the highest setting for $15 \mathrm{sec}$ and incubated on ice for $10 \mathrm{~min}$. Ice-cold CERII reagent $(22 \mu \mathrm{l})$ was added to the tube and then vortexed for $5 \mathrm{sec}$. Following incubating the tube on ice for $1 \mathrm{~min}$, the tube was vortexed for $5 \mathrm{sec}$ on the highest setting. The tube was centrifuged at maximum speed $(16,000 \times \mathrm{g})$ at $4^{\circ} \mathrm{C}$ for $5 \mathrm{~min}$ and then was immediately transferred to a clean pre-chilled tube. NER reagent (200 $\mu \mathrm{l})$ was then added, and the tube was vortexed for $15 \mathrm{sec}$. The sample was placed on ice and then continually vortexed for $15 \mathrm{sec}$ every $10 \mathrm{~min}$ for a total of $40 \mathrm{~min}$. The tube was centrifuged at maximum speed $(16,000 \mathrm{x} \mathrm{g})$ at $4^{\circ} \mathrm{C}$ for $10 \mathrm{~min}$, leaving the supernatant (nuclear extract). Nuclear proteins were stored at $-80^{\circ} \mathrm{C}$ until use.
Statistical analysis. Data are presented as the mean \pm standard deviation. All data were analyzed using the SPSS statistical software package (version, 19.0; IBM SPSS, Armonk, NY, USA). The statistical significance of differences in mean values was determined using the Student's t-test. $\mathrm{P}<0.05$ was considered to indicate a statistically significant difference.

\section{Results}

AhR knockout mice are not sensitized to KGF-induced intestinal epithelial cell proliferation. KGF, a classical growth factor, serves an important role in intestinal epithelial cell proliferation $(20,21)$. Immunohistochemical analysis was used to detect intestinal epithelial cell proliferation, and PCNA-positive cells were distributed in the crypt of Lieberkuhn of the small intestine. As presented in Fig. 1A and $\mathrm{C}$, it was identified that KGF significantly increased the number of PCNA-positive cells in the KGF group (42.8\%) when compared with the control group (23.28\%). However, the delivery of siRNA to target AhR mRNA transcripts resulted in a reduced rate of $\mathrm{KGF}$-induced epithelial cell proliferation $(24.06 \%)$. These data indicated that the absence of AhR resulted in reduced KGF-induced intestinal epithelial cell proliferation. Subsequently, changes in villus height and crypt depth were assessed. AhR knockdown led to a significant reduction in jejunal villus height $(274 \pm 70.9 \mu \mathrm{m})$ compared with the KGF group $(411 \pm 79.3 \mu \mathrm{m} ; \mathrm{P}<0.05)$. In addition, crypt depth was significantly reduced in the $\mathrm{KGF}+\mathrm{AhR}^{-/}$ group $(64.8 \pm 13.4 \mu \mathrm{m})$ when compared with the KGF group $(96 \pm 1.2 \mu \mathrm{m} ; \mathrm{P}<0.05$; Fig. 1B and D). Furthermore, intestinal wet weight and assessments of RNA and protein expression levels indicated that AhR deficiency abolished the sensitivity of the intestine to KGF (Table I). These findings suggested that AhR knockdown in intestinal epithelial cells results in reduced sensitivity to KGF.

Downregulation of KGFR after AhR knockout in vivo. KGF can modulate the proliferation of intestinal epithelial cells that specifically express KGFR, and this effect can be reversed by administering a blocking anti-KGFR antibody (22). As demonstrated in Fig. 2A and B, the effect of AhR knockout was assessed by western blotting, and it was identified that AhR expression was significantly knocked down when compared with the control. To investigate the mechanism whereby AhR knockout mice were made less sensitive to KGF in the small intestine, western blotting was performed to measure the expression of $\mathrm{KGFR}$ in $\mathrm{AhR}^{-/-}$mice. In physiological conditions, AhR knockout significantly reduced the expression of KGFR (0.65-fold, six mice/group; $\mathrm{P}<0.05$; Fig. 2C). Additionally, reduced levels of KGFR mRNA transcripts were measured by RT-qPCR in $\mathrm{AhR}^{-/}$epithelial cells (0.54-fold, six mice per group, $\mathrm{P}<0.05$; Fig. 2D). These findings indicated that AhR deletion induced the downregulation of KGFR expression, resulting in reduced intestinal cell sensitivity to growth stimulation induced by KGF.

Regulation of KGFR expression by the AhR-E2F1 pathway in vitro. To further investigate the effects of $\mathrm{AhR}$ on KGF signaling, LoVo cells were transfected with siRNA specific for AhR (siAhR). As presented in Fig. 3A, the effect of siAhR was 
Table I. Intestinal wet weight and levels of jejunal protein and RNA expression.

\begin{tabular}{lcccc}
\hline Variable & Control group & KGF group & KGF + AhRKO group & AhRKO group \\
\hline Protein $(\mathrm{mg} / \mathrm{cm})$ & $2.65 \pm 0.13$ & $3.02 \pm 0.56^{\mathrm{a}, \mathrm{b}}$ & $2.28 \pm 0.32$ & $1.86 \pm 0.27$ \\
RNA $(\mathrm{mg} / \mathrm{cm})$ & $29.9 \pm 6.1$ & $38.8 \pm 0.83^{\mathrm{a}, \mathrm{b}}$ & $25.2 \pm 1.8$ & $20.9 \pm 5.1$ \\
Intestinal wet weight $(\mathrm{mg} / 10 \mathrm{~cm})$ & $488.7 \pm 6.9$ & $553.4 \pm 8.6^{\mathrm{a}, \mathrm{b}}$ & $449.5 \pm 10.8$ & $401.8 \pm 9.5$ \\
\hline
\end{tabular}

Data are presented as mean \pm standard deviation. Tissues were harvested following intraperitoneally administration at $5 \mathrm{mg} / \mathrm{kg} / \mathrm{day}$ for $5 \mathrm{days}$. ${ }^{\text {a }} \mathrm{P}<0.05$ vs. AhRKO group; ${ }^{\mathrm{P}}<0.05$ vs. KGF $+\mathrm{AhRKO}$ group. KGF, keratinocyte growth factor; AhRKO, aryl hydrocarbon receptor knockout.

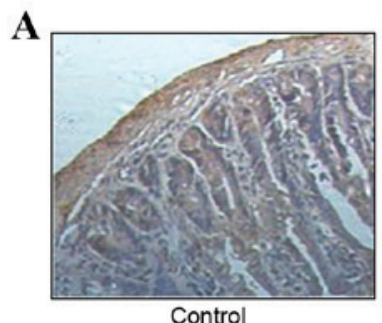

Control

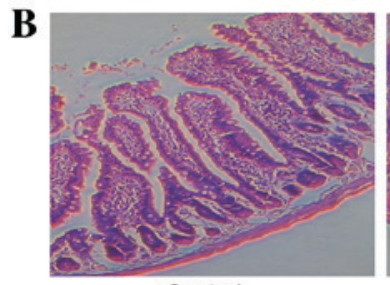

Control

C

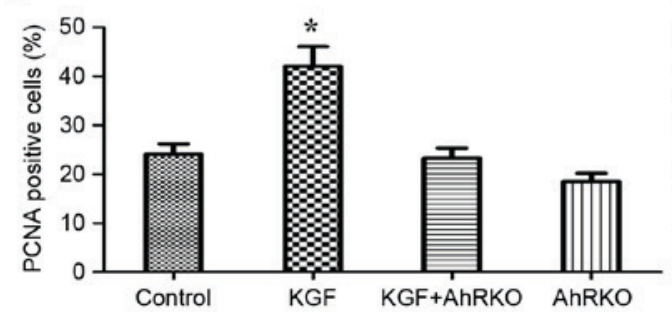

KGF

KGF
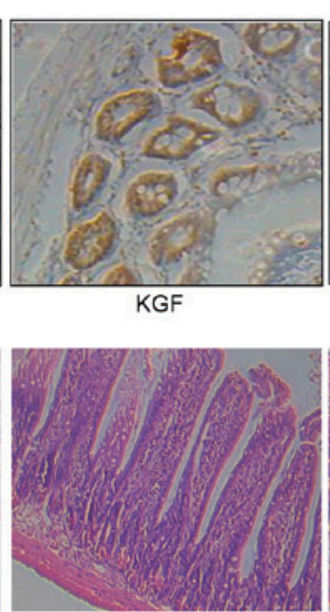

D

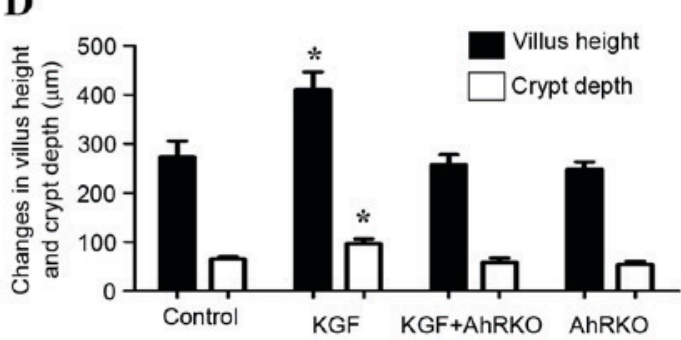

Figure 1. AhR knockout mice are not sensitized to KGF-induced intestinal epithelial cell proliferation. (A) Microscopic images (x200) of PCNA-stained intestine. (B) Microscopic images (x200) of hematoxylin and eosin stained intestine. (C) KGF significantly increased the number of PCNA-positive cells in the KGF group when compared with the control group, while AhR knockout reduced KGF-induced epithelial cell proliferation. (D) AhRKO led to a significant reduction in jejunal villus height and crypt depth compared with the KGF group, while KGF administration did not induce significant changes in the KGF + AhRKO group compared with the AhRKO group. ${ }^{*} \mathrm{P}<0.05$ vs. Control. AhR, aryl hydrocarbon receptor; KGF, keratinocyte growth factor; PCNA, proliferating cell nuclear antigen; AhRKO, AhR knockout.

assessed by western blotting, and it was demonstrated that AhR expression was significantly knocked down when compared with the control. Furthermore, following transfecting LoVo cells with siAhR for $24 \mathrm{~h}$, western blotting results indicated reduced levels (0.57) of KGFR protein expression in AhR-silenced cells compared against the control group (Fig. 3B). In accordance with the western blotting results, downregulated levels $(0.46)$ of KGFR mRNA transcripts were detected by RT-qPCR in AhR-silenced epithelial cells (Fig. 3C). Therefore, these findings indicated that KGFR expression may be regulated by AhR. Following this, the authors explored the mechanism whereby AhR regulates KGFR expression. As previous studies have reported that FGFR expression can be regulated by E2F family members $(8,9,23)$, the present study focused on the nuclear transcription factor E2F. As detailed in Fig. 3D-F, reduced protein levels of KGFR could be observed in LoVo cells in which E2F1 was knocked-out compared with the control group, suggesting that this transcription factor (E2F1) may affect KGFR expression. Following demonstrating that the transcription factor E2F1 may meditate KGFR expression, whether AhR could influence the function of E2F1 to regulate the expression of KGFR was assessed. Cells were transfected with siRNA to target AhR, and there was a significant reduction of $\mathrm{E} 2 \mathrm{~F} 1$ in the nucleus detected (Fig. 3G-I). In conclusion, these findings demonstrated that the AhR-E2F1 pathway regulates KGFR expression in intestinal epithelial cells.

AhR knockdown LoVo cells are less sensitized to KGF stimulation in vitro. To test whether knockdown of AhR expression altered KGF signaling, serum-starved LoVo cells with or without 

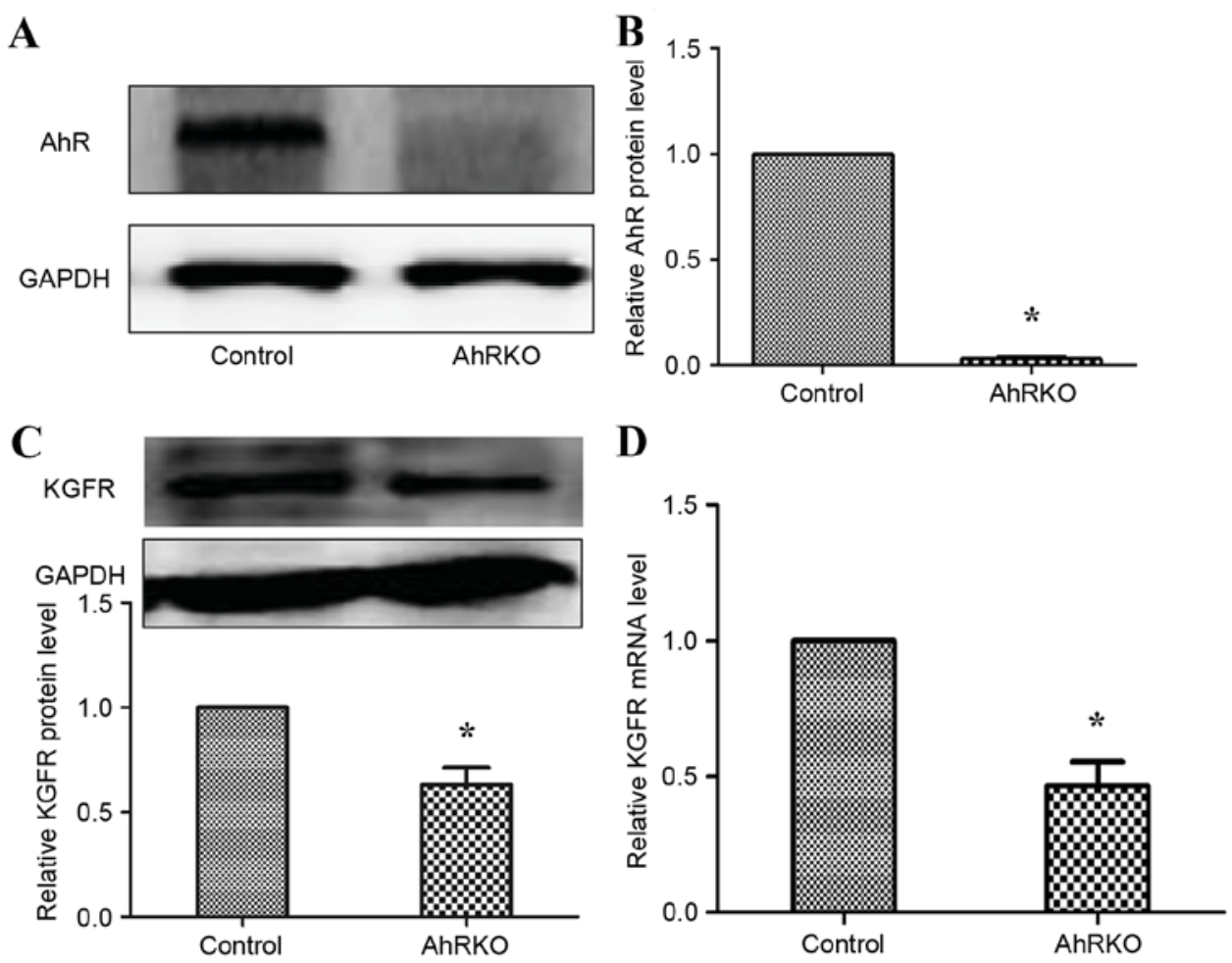

Figure 2. Downregulation of KGFR expression following ablation of AhR expression in vivo. (A and B) AhR was knocked out successfully. (C) Knockout of AhR significantly reduced the expression of KGFR at the protein level. (D) Knockout of AhR significantly reduced the expression of KGFR at the mRNA level. ${ }^{*} \mathrm{P}<0.05$ vs. Control. KGFR, keratinocyte growth factor receptor; AhR, aryl hydrocarbon receptor; AhRKO, aryl hydrocarbon receptor knockout.

A

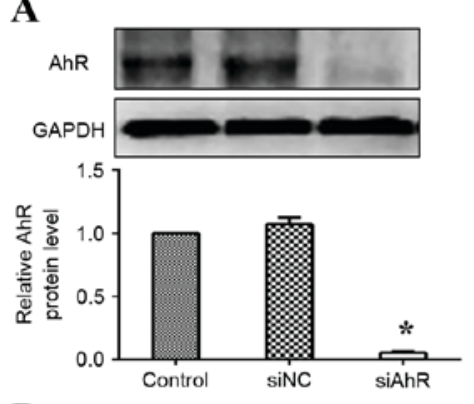

D
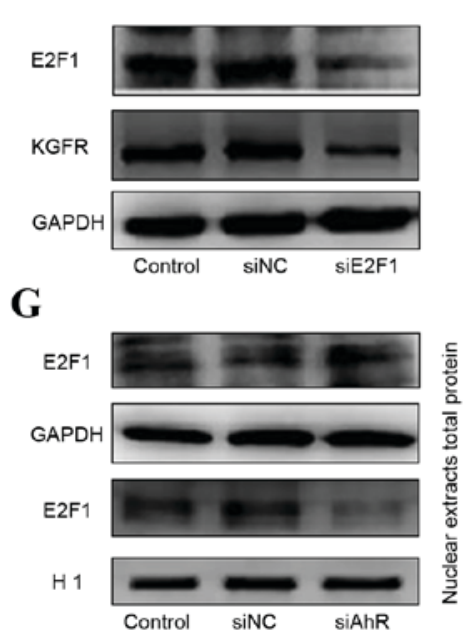

B

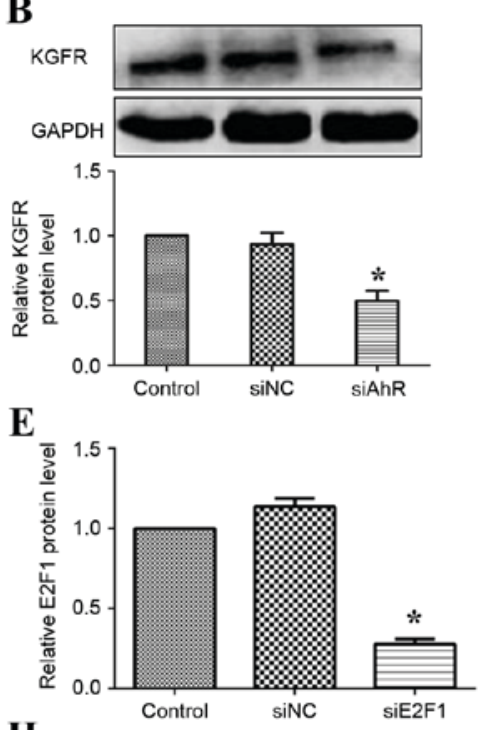

H

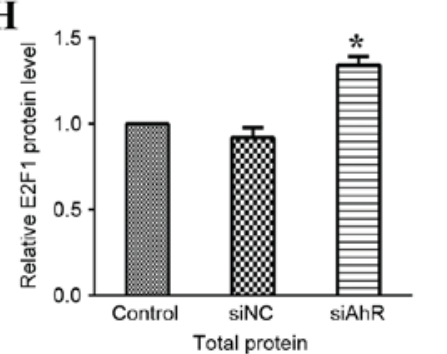

C
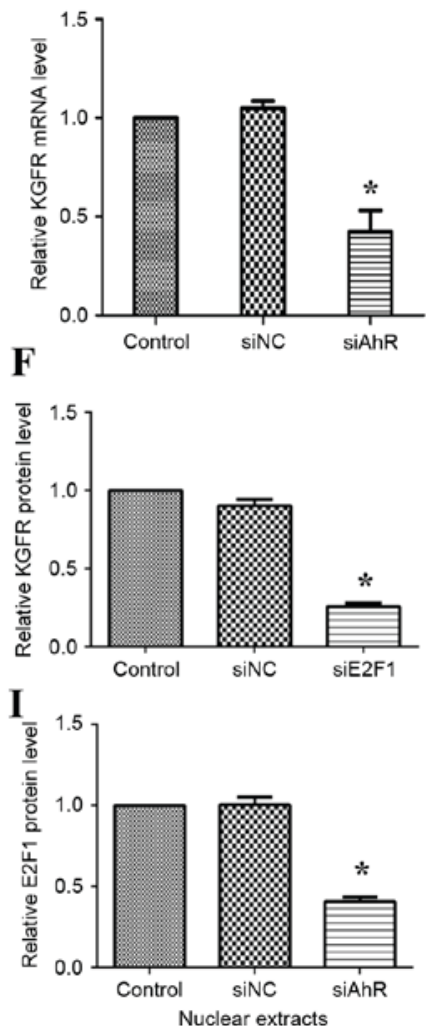

Figure 3. Regulation of KGFR expression by the AhR-E2F1 pathway in vitro. (A) AhR expression was significantly knocked-down using siAhR. (B) KGFR protein levels were significantly reduced in LoVo cells that were transfected with siAhR for $24 \mathrm{~h}$. (C) The mRNA transcript levels of KGFR were also significantly reduced in AhR-silenced LoVo cells. (D-F) When E2F1 was knocked-out, protein expression levels of KGFR were significantly reduced. (G-I) In LoVo cells in which AhR was silenced, E2F1 protein expression levels were significantly reduced in the nucleus. "P<0.05 vs. Control. KGFR, keratinocyte growth factor receptor; AhR, aryl hydrocarbon receptor; si, small-interfering RNA. 

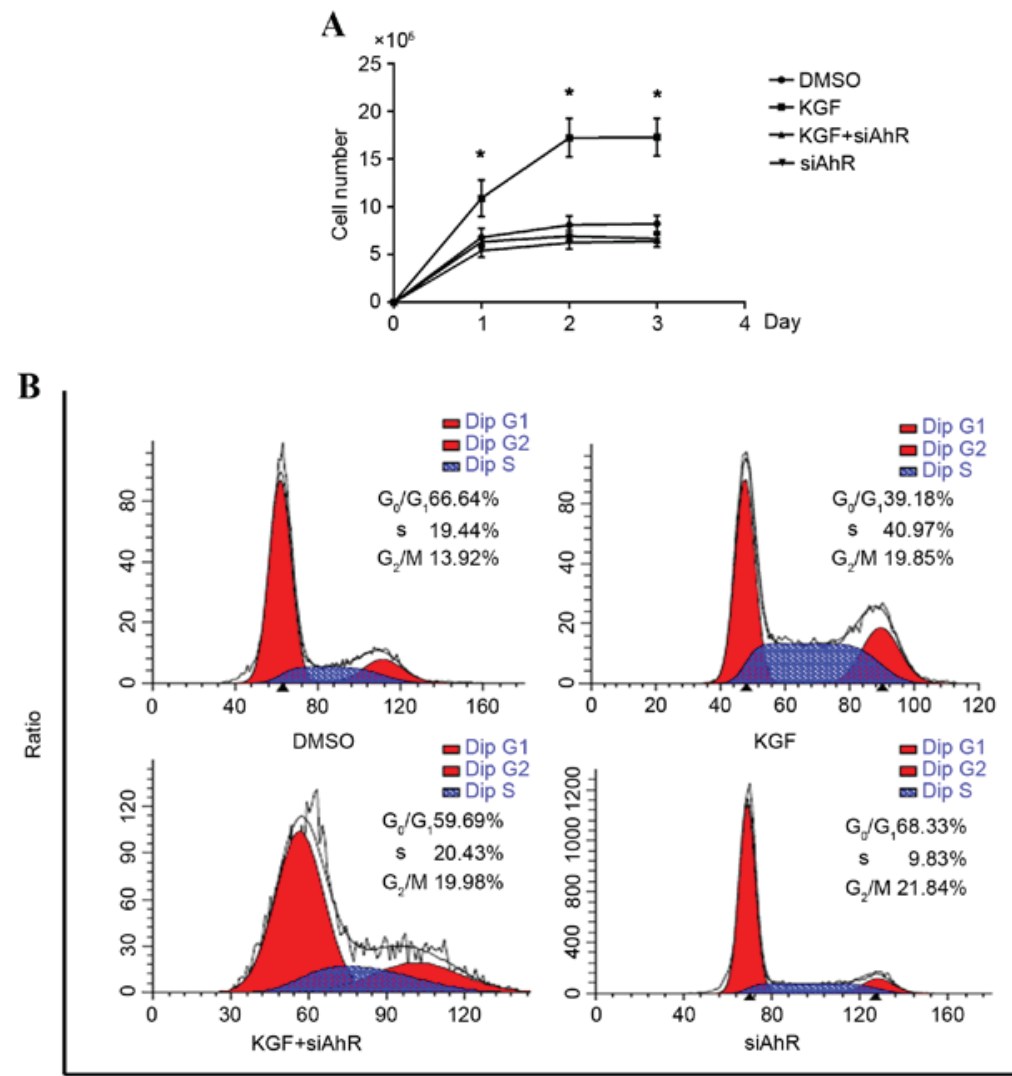

DNA content

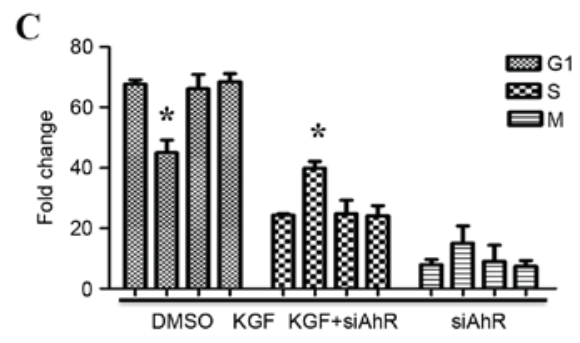

Figure 4. AhR knockdown LoVo cells are less sensitive to KGF in vitro. (A) Cell numbers in the KGF group were significantly increased compared to that of the other groups. (B and C) The ratio of cells of KGF group in G0/G1 phase was significantly lower than other groups, and the ratio of cells of KGF group in $\mathrm{S}$ phase was significantly lower than other groups. ("P<0.05 vs. all other groups). AhR, aryl hydrocarbon receptor; KGF, keratinocyte growth factor; DMSO, dimethylsulfoxide; si, small interfering.

AhR knockdown were stimulated with KGF (100 ng/ml); cell counting and flow cytometry analysis were conducted to assess cell viability. Following adding KGF, the proliferation rate of LoVo cells increased significantly compared with untreated control cells, and this effect was abolished by siAhR treatment. The present finding of siAhR-meditated inhibition of cell number in LoVo cells was confirmed by trypan blue/hemocytometer and flow cytometric analyses. In the KGF group, cell numbers were significantly increased compared with the other groups (Fig. 4A). KGF caused a significant reduction in the relative number of G0/G1 cells and a significant associated increase in S phase cells. At $24 \mathrm{~h}, 66.64 \%$ cells were in G0/G1 phase for untreated cells compared with $39.18 \%$ for KGF-treated cells. Knockdown of AhR expression alone had a slight influence on the number of cells in G0/G1 phase. However, for cells treated with siAhR + KGF compared to KGF alone, the \% of cells in G0/G1 phase was $59.69 \%$ compared with $39.18 \%$ (Fig. 4B and C), respectively. These data indicated that AhR knockdown may attenuate KGF-induced cell proliferation.

\section{Discussion}

In the current study, it was identified that $\mathrm{AhR}^{-/}$mice were not responsive to KGF-induced intestinal proliferation effects or intestinal morphological changes under physiological conditions. Moreover, KGFR expression levels were significantly lower in AhR knockout intestinal epithelial cells. Silencing of E2F1 may significantly reduce the expression of KGFR, while silencing of AhR could markedly lower the expression of E2F1. Together, these findings demonstrated that the AhR-E2F1-KGFR signaling pathway is involved in KGF signaling in intestinal epithelial cells. 
KGF is a classical cell growth factor that has been widely studied. For example, KGF improves epithelial function after massive small bowel resection (11) and KGF gene therapy was demonstrated to ameliorate ulcerative colitis in rats (16). Furthermore, in the present study, knockdown of AhR expression may abolish KGF-induced intestinal proliferation in AhR knockout mice. Villus height, crypt depth, intestinal wet weight, RNA levels and protein expression analysis also indicated that AhR knockout mice presented compromised KGF-induced intestinal changes. Previous studies have reported that $\mathrm{AhR}$, as a conserved nuclear transcription protein, serves an important role in cell proliferation (24-27). Interestingly, other work in the field found that AhR regulates the expression of receptors that meditated cell survival and growth. For example, Lee et al (16) reported that AHR supported the presence of NKp46 ILCs and, partially, lymphoid tissue inducer-like ILCs in the intestinal lamina propria through the induction of Notch receptors. Additionally, AhR-dependent c-Kit expression is critical for the homeostasis of invariant $\gamma \delta \mathrm{T}$ cells in the murine epidermis (28).

In the present study, KGFR expression was downregulated in AhR knockout mice and AhR knockdown LoVo cells. These findings suggested that AhR ablation induced the downregulation of KGFR expression, thereby reducing intestinal cell sensitively to KGF-stimulated proliferation.

Few studies have characterized the molecular mechanisms that regulate human KGFR expression in intestinal epithelial cells. Koga et al (29) reported that the expression level of KGFR significantly increased when angiotensin II (ATII) was blocked by Losartan in a small bowel resection mouse model. Recently, it has been reported that the transcription factor E2F1 can bind to the KGFR promoter and activate KGFR expression in MCF-7 and HEK293 cells (30). Furthermore, expression of the human FGFR1 and murine FGFR2 genes can be directly regulated by $\operatorname{E} 2 \mathrm{~F} 1(8,23)$. The present finding that KGFR expression was reduced in colon cells with knockdown of E2F1 is consistent with these previous studies $(8,23)$. As a nuclear transcription factor, once E2F1 traffics to the nucleus, it exerts its transcription activity on the FGFR2 gene by direct binding to the KGFR promoter (30). In the current study, significantly reduced levels of nuclear E2F1 in the AhR knockout group were detected when compared with the control group. This finding suggested that KGFR expression may be regulated via the AhR-E2F1 pathway. However, the mechanism whereby AhR regulates trafficking of the E2F1 transcription factor from the cytoplasm to the nucleus remains unclear. Moreover, cell counting revealed that KGF-induced cell proliferation was reduced and flow cytometric analyses revealed that the cell cycle profile was notably altered when AhR was knocked-down, as there was a significant increase in the percentage of cells in G0/G1 phase compared with the KGF-alone treated group.

In summary, the AhR-E2F1-KGFR signaling pathway was demonstrated to be involved in KGF-induced intestinal epithelial cell proliferation. Further studies are required to understand the molecular mechanisms of KGF-induced intestinal epithelial cell growth and proliferation in greater detail.

\section{Acknowledgements}

The present study was supported by grants from the National Natural Science Foundation of China (grant nos. NSFC 81330013 to Hua Yang, and NSFC 81300275 to Lihua Sun) and the Program of Changjiang Scholars and Innovative Research (grant no. IRT 13050 to H.Y.).

\section{References}

1. Boismenu R and Havran WL: Modulation of epithelial cell growth by intraepithelial gamma delta T cells. Science 266: 1253-1255, 1994.

2. Cai Y, Wang W, Liang H, Sun L, Teitelbaum DH and Yang H: Keratinocyte growth factor pretreatment prevents radiation-induced intestinal damage in a mouse model. Scand $\mathrm{J}$ Gastroenterol 48: 419-426, 2013.

3. Chen Y, Chou K, Fuchs E, Havran WL and Boismenu R: Protection of the intestinal mucosa by intraepithelial gamma delta T cells. Proc Natl Acad Sci USA 99: 14338-14343, 2002.

4. Burbach KM, Poland A and Bradfield CA: Cloning of the Ah-receptor cDNA reveals a distinctive ligand-activated transcription factor. Proc Natl Acad Sci USA 89: 8185-8189, 1992.

5. Wormke M, Stoner M, Saville B, Walker K, Abdelrahim M, Burghardt R and Safe S: The aryl hydrocarbon receptor mediates degradation of estrogen receptor through activation of proteasomes. Mol Cell Biol 23: 1843-1855, 2003.

6. Cai Y, Wang W, Liang H, Sun L, Teitelbaum DH and Yang H: Keratinocyte growth factor improves epithelial structure and function in a mouse model of intestinal ischemia/reperfusion. PLoS One 7: e44772, 2012.

7. Hankinson O: The aryl hydrocarbon receptor complex. Annu Rev Pharmacol Toxicol 35: 307-340, 1995.

8. Tashiro E, Minato Y, Maruki H, Asagiri M and Imoto M: Regulation of FGF receptor-2 expression by transcription factor E2F-1. Oncogene 22: 5630-5635, 2003.

9. Tashiro E, Maruki H, Minato Y, Doki Y, Weinstein IB and Imoto M: Overexpression of cyclin D1 contributes to malignancy by up-regulation of fibroblast growth factor receptor 1 via the pRB/E2F pathway. Cancer Res 63: 424-431, 2003.

10. Yang H, Wildhaber BE and Teitelbaum DH: 2003 Harry M. Vars Research Award. Keratinocyte growth factor improves epithelial function after massive small bowel resection. JPEN J Parenter Enteral Nutr 27: 198-207, 2003.

11. Liu CJ, Jin JD, Lv TD, Wu ZZ and Ha XQ: Keratinocyte growth factor gene therapy ameliorates ulcerative colitis in rats. World $\mathrm{J}$ Gastroenterol 17: 2632-2640, 2011

12. Tsuji N, Fukuda K, Nagata Y, Okada H, Haga A, Hatakeyama S, Yoshida S, Okamoto T, Hosaka M, Sekine K, et al: The activation mechanism of the aryl hydrocarbon receptor (AhR) by molecular chaperone HSP90. FEBS Open Bio 4: 796-803, 2014.

13. Hao $\mathrm{N}$ and Whitelaw ML: The emerging roles of AhR in physiology and immunity. Biochem Pharmacol 86: 561-570, 2013.

14. Furumatsu K, Nishiumi S, Kawano Y, Ooi M, Yoshie T, Shiomi Y, Kutsumi H, Ashida H, Fujii-Kuriyama Y, Azuma T and Yoshida $\mathrm{M}$ : A role of the aryl hydrocarbon receptor in attenuation of colitis. Dig Dis Sci 56: 2532-2544, 2011.

15. Monteleone I, MacDonald TT, Pallone F and Monteleone G: The aryl hydrocarbon receptor in inflammatory bowel disease: Linking the environment to disease pathogenesis. Curr Opin Gastroenterol 28: 310-313, 2012.

16. Lee JS, Cella M, McDonald KG, Garlanda C, Kennedy GD, Nukaya M, Mantovani A, Kopan R, Bradfield CA, Newberry RD and Colonna M: AHR drives the development of gut ILC22 cells and postnatal lymphoid tissues via pathways dependent on and independent of Notch. Nat Immunol 13: 144-151, 2011.

17. Qiu J, Heller JJ, Guo X, Chen ZE, Fish K, Fu YX and Zhou L: The aryl hydrocarbon receptor regulates gut immunity through modulation of innate lymphoid cells. Immunity 36: 92-104, 2012.

18. Kiss EA, Vonarbourg C, Kopfmann S, Hobeika E, Finke D, Esser $\mathrm{C}$ and Diefenbach A: Natural aryl hydrocarbon receptor ligands control organogenesis of intestinal lymphoid follicles. Science 334: 1561-1565, 2011.

19. Livak KJ and Schmittgen TD: Analysis of relative gene expression data using real-time quantitative PCR and the 2(-Delta Delta C(T)) Method. Methods 25: 402-408, 2001. 
20. Jonas CR, Gu LH, Nkabyo YS, Mannery YO, Avissar NE, Sax HC, Jones DP and Ziegler TR: Glutamine and KGF each regulate extracellular thiol/disulfide redox and enhance proliferation in Caco-2 cells. Am J Physiol Regul Integr Comp Physiol 285: R1421-R1429, 2003.

21. Hille A, Grüger S, Christiansen H, Wolff HA, Volkmer B, Lehmann J, Dörr W and Rave-Fränk M: Effect of tumour-cell-derived or recombinant keratinocyte growth factor (KGF) on proliferation and radioresponse of human epithelial tumour cells (HNSCC) and normal keratinocytes in vitro. Radiat Environ Biophys 49: 261-270, 2010.

22. Mehta M, Kesinger JW, Zang XP, Lerner ML, Brackett DJ, Brueggemeier RW, Li PK and Pento JT: Influence of novel KGFR tyrosine kinase inhibitor on KGF-mediated proliferation of breast cancer. Anticancer Res 30: 4883-4889, 2010

23. Kanai $\mathrm{M}$, Tashiro $\mathrm{E}$, Maruki $\mathrm{H}$, Minato $\mathrm{Y}$ and Imoto $\mathrm{M}$ : Transcriptional regulation of human fibroblast growth factor receptor 1 by E2F-1. Gene 438: 49-56, 2009.

24. Furukawa K, Matsumoto K, Nagayasu T, Yamamoto-Fukuda T, Tobinaga S, Abo T, Yamasaki N, Tsuchiya T, Miyazaki T, Kamohara $\mathrm{R}$, et al: Intratracheal administration of recombinant human keratinocyte growth factor promotes alveolar epithelial cell proliferation during compensatory lung growth in rat. Acta Histochem Cytochem 46: 179-185, 2013.
25. Hirobe T, Hasegawa K, Furuya R, Fujiwara R and Sato K: Effects of fibroblast-derived factors on the proliferation and differentiation of human melanocytes in culture. J Dermatol Sci 71: 45-57, 2013

26. Li GJ, Jiang DY, Zong XL and Xu X: Keratinocyte growth factor phage model peptides can promote human oral mucosal epithelial cell proliferation. Oral Surg Oral Med Oral Pathol Oral Radiol 116: e92-e97, 2013.

27. Playford RJ, Marchbank T, Mandir N, Higham A, Meeran K, Ghatei MA, Bloom SR and Goodlad RA: Effects of keratinocyte growth factor (KGF) on gut growth and repair. J Pathol 184: 316-322, 1998.

28. Kadow S, Jux B, Zahner SP, Wingerath B, Chmill S, Clausen BE, Hengstler $\mathrm{J}$ and Esser $\mathrm{C}$ : Aryl hydrocarbon receptor is critical for homeostasis of invariant gammadelta $\mathrm{T}$ cells in the murine epidermis. J Immunol 187: 3104-3110, 2011.

29. Koga H, Yang H, Haxhija EQ and Teitelbaum DH: The role of angiotensin II type 1a receptor on intestinal epithelial cells following small bowel resection in a mouse model. Pediatr Surg Int 24: 1279-1286, 2008

30. D'AmiciS, Ceccarelli S, Vescarelli E, Romano F, Frati L, Marchese C and Angeloni A: TNFo modulates fibroblast growth factor receptor 2 gene expression through the $\mathrm{pRB} / \mathrm{E} 2 \mathrm{~F} 1$ pathway: Identification of a non-canonical E2F binding motif. PLoS One 8: e61491, 2013. 